\title{
Thoughts on the Implementation of Online and Offline Hybrid Teaching of University Computer Courses
}

\author{
Cheng Xu \\ College of Computer Science and Technology, Yangtze University, Jingzhou, Hubei, China
}

\begin{abstract}
Based on the continuous advancement of higher education reform, the implementation of online and offline hybrid teaching has become a new direction. Combining online teaching and offline teaching, constructing a hybrid teaching model can bring a whole new experience to teaching activities. For university computer courses, the implementation of online and offline hybrid teaching is very necessary, which can reflect positive effects in many aspects. Based on this, this article first analyzes the main points of online and offline hybrid teaching, discusses its positive effects on university computer courses, analyzes its specific strategies for implementation, and puts forward a few points for attention, hoping to provide some references for university computer course teachers.
\end{abstract}

Key words: university; computer courses; online and offline; hybrid teaching

\section{Introduction}

In recent years, the rapid development of information technology has promoted real progress in online teaching. Especially in 2020, affected by some special factors, colleges and universities across the country have implemented online teaching for a period of time. However, as the social order returns to the right track, educational activities have gradually returned to the normal form of the past, which has led to the gradual abandonment of online teaching and the return of course teaching to the previous offline classroom mode. From the perspective of the development of education and teaching, online teaching is a future trend, but the basic conditions for a complete transformation to online teaching are not yet available. Therefore, it is necessary to promote online and offline hybrid teaching, combining the two, and applying them comprehensively to keep teaching activities in a relatively stable environment. For university computer courses, it is necessary to realize the connotation of online and offline hybrid teaching, and use it to develop innovative construction of computer course teaching, and effectively improve the effectiveness of computer course teaching.

\section{The Main Points of Online and Offline Mixed Teaching}

Online and offline hybrid teaching is a comprehensive teaching mode. Its two aspects, online learning and offline teaching, correspond to each other, connect with each other, and become a whole. These two aspects work together to develop teaching so that students can participate in learning separately from two channels, so as to form an effective understanding and mastery of curriculum knowledge. With time of appearance is not long, Online and offline hybrid teaching is a relatively new teaching mode. When putting it into practice, course teachers need to effective understand some basic points:

Copyright (C 2021 by author(s) and Frontier Scientific Research Publishing Inc.

This work is licensed under the Creative Commons Attribution International License (CC BY 4.0).

http://creativecommons.org/licenses/by/4.0/ 
The first is online resources. Carrying out online learning must have corresponding online learning resources. Online learning is carried out by students on their own mostly, while teachers are less involved. And students need corresponding learning resources for autonomous learning. Therefore, it is necessary to pay attention to the construction of online learning resources in the implementation of online and offline hybrid teaching, and create diversified learning resources combined with the actual curriculum, which are provided for students' online learning.

The second is offline activities. Online and offline hybrid teaching should not only pay attention to the online learning of students, but also pay attention to the innovation of offline teaching. The traditional mode of offline teaching is mostly limited to theoretical explanation, lacking corresponding practical activities, which is not conducive to the development of students' practical ability. Especially for courses that are very practical, such as computers, insufficient practical activities will lead to poor computer practical skills. Therefore, under the online and offline hybrid teaching model, attention should be paid to the construction of offline teaching and practice activities, so as to provide students with sufficient opportunities for practice, so that students can develop good computer practice skills.

The third is evaluated process. It refers to the need to make corresponding evaluations for both the online learning process and the offline teaching process, to understand the specific learning situation of students online and offline, and to find students' learning problems and knowledge weaknesses through evaluations, and then make targeted suggestions to guide students to correct, so that teaching activities can achieve better development.

\section{The Positive Effect of Online and Offline Hybrid Teaching on University Computer Courses}

For the teaching of university computer courses, the implementation of online and offline hybrid teaching can play a positive role in many aspects, which requires effective understanding of course teachers. First, it can realize the extension and expansion of computer teaching. In the past, the teaching of computer courses was limited to the classroom, and students' learning was also limited to the classroom. Few students were able to study independently outside, which led to the poor learning effect of many students. While online and offline hybrid teaching builds an online learning platform for students, which can guide students to participate in learning outside of class, and realize the expansion of computer teaching from inside class to outside class, allowing students to participate in learning more deeply. Second, it can strengthen the learning interaction between students. In traditional computer teaching classrooms, students have insufficient interaction with each other, and most of them are in an individualized learning state, with little learning cooperation between them. While online and offline hybrid teaching can provide students with interactive platforms and places through online learning platforms and offline practical activities, which enhances the learning interaction between students. Third, it can enhance the flexibility of computer teaching. Teachers can flexibly switch between online platforms and offline classrooms, which make the development of teaching activities in a dynamic change, so that the teaching of computer courses can always remain novel, and students can feel the joy of learning, so as to generate strong learning enthusiasm.

\section{Strategies on the Implementation of Online and Offline Hybrid Teaching of University}

\section{Computer Courses}

\subsection{Build an online learning platform}

The implementation of online and offline hybrid teaching should first establish a corresponding online learning platform, so as to provide a basic environment for online learning. There are generally two ways of constructing online learning platforms. One is to use some ready-made learning platforms to build an online learning platform in combination with the teaching needs of computer courses. For example, there are many online education platforms, such as "XuetangX", "Rain Classroom", "Cloud classroom of Netease" and so on. We could use these ready-made online education platforms to 
build targeted online learning platforms based on some of their existing functions. The second is to build an online learning platform independently, which requires the use of computer technology and information technology to independently develop an online learning system, and build different data interfaces based on the PC and mobile phones, so that students can $\log$ in to the system and start online learning from channels such as computers and mobile phones.

\subsection{Create online learning resources}

After building an online learning platform, further construction of online learning resources is needed. The online learning platform is just a carrier, and online learning resources are the key to driving students to start online learning. Online and offline hybrid teaching places special emphasis on online resources. Therefore, computer course teachers should pay attention to the construction of online learning resources. First, it is possible to digitally construct various teaching resources accumulated in the past, such as PPT courseware, learning micro-classes, etc., and upload them to the online learning platform after sorting them. Second, start from the Internet channels and collect relevant learning resources, such as open computer courses on the Internet, computer boutique MOOCs from brother schools, etc., organize them according to a certain knowledge structure, and upload them to online platforms for students to learn and use. Third, according to current teaching needs, we should independently design some learning resources, such as pre-class preparation materials, after-class exercises, etc., and upload them to the online platform.

\subsection{Instruct students to learn online}

After building an online platform and creating online learning resources, it is necessary to guide students to start online learning based on this. When carrying out online learning, we need to pay attention to the before class and after class. The after class stage is mainly to guide students to start online preview. Before teaching the knowledge of a certain section of the computer course, teachers can extract the main points of knowledge from it, design a learning micro-class, and set some thinking questions in it. Teachers upload the learning micro-classes to the online learning platform, and require students to $\log$ on to the online platform to complete the before class preview before the start of class teaching, answer relevant thinking questions, and submit answers online. The after class session is mainly to guide students' online exercises and review. It requires teachers to design corresponding computer practice tasks, and can design practical operation exercises, allowing students to carry out operation exercises through the online platform. At the same time, the chapter knowledge is summarized based on the mind map and uploaded to the online platform, so that students can conduct a centralized knowledge review after class, thereby strengthening the grasp of computer knowledge.

\subsection{Optimize offline teaching}

Offline teaching needs to pay attention to the docking with online learning and the optimization of its methods. First of all, before the start of offline teaching, teachers need to log on to the online learning platform to understand the students' online preview, and analyze the key and difficult points of knowledge that students face in the preview based on the students' answers to the preview questions. These important and difficult points need to be grasped in classroom teaching. Second, we should innovate offline classroom teaching methods. In offline classrooms, attention should be paid to the innovative construction of teaching methods. Different methods such as question list guidance and group cooperative learning can be used to replace the traditional unilateral teaching mode. Finally, we need to pay attention to constructing offline practical activities. Taking computer teaching as an example, students can be organized to participate in computer skills competitions, and other practical activities can be designed to guide students to participate in order to form an effective grasp of computer technology in practice.

\subsection{Implement teaching evaluation}

Online and offline hybrid teaching also needs to evaluate the online and offline learning process, and grasp the 
learning effect of students. For the online learning process, we can design an independent evaluation function based on an online learning platform, that is, build an independent evaluation question bank. Students enter the question bank, and the system randomly assigns some questions which contain theoretical and practical questions. Students answer these questions, and the system automatically makes evaluations. Through these evaluations, students' mastery of computer knowledge is analyzed. For the offline learning process, comprehensive computer practice tasks can be designed to guide students to participate in comprehensive practice. According to the specific performance of the students in the comprehensive practice, the use of knowledge, etc., the students' learning situation can be judged, the existing problems can be pointed out, and learning suggestions can be put forward.

\section{Points for Attention in Implementing Online and Offline Hybrid Teaching in University} Computer Courses

In the implementation of online and offline hybrid teaching in computer courses, there are still some precautions that need to be grasped, which requires a clear understanding of computer teachers. The first is to maintain the collaborative construction of online learning and offline teaching. Online and offline hybrid teaching is divided into two parts: online learning and offline teaching. In practice, it is necessary to maintain the synergy of online learning and offline teaching, so that the two can coordinate with each other and develop in the same direction, so as to provide strong support for computer teaching. Therefore, as a computer course teacher, it is necessary to coordinate online learning and offline teaching, and reasonably arrange learning content. The second is to strengthen the control of the teaching process. Both online learning and offline teaching need to be effectively controlled to ensure that the teaching activities achieve the desired results. Therefore, based on the actual development of computer courses, computer teachers should strengthen the management and control of the online learning process and the offline teaching process, standardize the learning behavior of students, and ensure that students can deeply participate.

\section{Conclusions}

For the teaching of university computer courses, the current new era needs to pay attention to the construction of online and offline hybrid teaching models, which requires the establishment of online learning platforms, creation of online learning resources, and guiding students to conduct before class preview and after class exercises and review on the online platform, optimizing offline teaching and doing a good job of teaching evaluation at the same time, and comprehensively promoting the implementation of online and offline mixed teaching.

\section{Conflicts of Interest}

The author declares no conflicts of interest regarding the publication of this paper.

\section{References}

[1] Li Y., Cheng X. and Yang Y.L. (2020). Research on Online and Offline Hybrid Teaching of University Computer Basis. China Computer \& Communication, 449(07): 239-240.

[2] Liu Y.T. and Liu Y. (2020). Online and Offline Hybrid Teaching Reform of Computer Public Training Course in Higher Vocational Colleges. Experimental Technology and Management, 286(06): 250-252.

[3] Yang T. (2020). Research on the Application of Online and Offline Hybrid Teaching in Colleges and Universities. Journal of International Education Forum, 2(07): 1-2.

[4] Wei C.X. and Ma X.J. (2020). Research on the "Golden Course" Teaching Mode of Computer Basic in Online and Offline Hybrid Universities. Journal of Anyang Normal University, 127(05): 150-152.

[5] Yang Y.K. and Li F. (2019). Practice of Online and Offline Hybrid Teaching in the Course. Journal of Fujian Computer, 35(11): 111-112. 